\title{
MERCEDES TRENTINI: A TRAJETÓRIA PROFISSIONAL E SUA CONTRIBUIÇÃO NA INOVAÇÃO DA PESQUISA NA ENFERMAGEM
}

\author{
Miriam Süsskind Borenstein ${ }^{1}$, Maria Itayra Padilha², Juliana Bonetti de Carvalho³, Daniela Simoni Espindola4, \\ Joanara Rozane de Fontoura Winters ${ }^{5}$, Camilla Telemberg Sell ${ }^{6}$
}

\footnotetext{
${ }^{1}$ Doutora em Enfermagem. Professora aposentada do Programa de Pós-Graduação em Enfermagem (PEN) da Universidade Federal de Santa Catarina (UFSC). Florianópolis, Santa Catarina, Brasil. E-mail: miriam@nfr.ufsc.br

${ }^{2}$ Doutora em Enfermagem. Professora do PEN/UFSC. Pesquisadora do CNPq. Florianópolis, Santa Catarina, Brasil. E-mail: itayra. padilha@ufsc.br

${ }^{3}$ Doutoranda do PEN/UFSC. Florianópolis, Santa Catarina, Brasil. E-mail: julianapersempre@hotmail.com

${ }^{4}$ Doutora em Enfermagem. Fisioterapeuta, coordenadora da UTI geral do Hospital Regional de São José. Florianópolis, Santa Catarina, Brasil. E-mail: daniela.sesp@gmail.com

${ }^{5}$ Doutoranda do PEN/UFSC. Docente do Instituto Federal de Santa Catarina - Campus Joinville. Florianópolis, Santa Catarina, Brasil. E-mail: joanaraw@ifsc.edu.br

${ }^{6}$ Mestre em Enfermagem. Enfermeira da UTI da Secretaria de Estado da Saúde. Florianópolis, Santa Catarina, Brasil. E-mail: camillasell@hotmail.com
}

\section{RESUMO}

Objetivo: historicizar a trajetória profissional de Mercedes Trentini e sua contribuição para a enfermagem brasileira, a partir de sua biografia. Método: estudo qualitativo de abordagem sócio-histórica, cujos dados foram coletados através do método da História Oral Biográfica e da Pesquisa Documental.

Resultados: a partir da análise dos dados estabeleceram-se quatro categorias: 1) A inserção no mundo da enfermagem e no Curso de Graduação; 2) A trajetória na Pós-Graduação em Enfermagem; 3) A criação do Núcleo de Pesquisa em Enfermagem e Saúde no Cuidado a Pessoas com Doenças Crônicas; e 4) Os caminhos trilhados para a criação da Pesquisa Convergente-assistencial.

Conclusão: a Professora Mercedes Trentini caracterizou-se como uma pessoa original, inovadora, comprometida com a profissão de enfermagem, e, em decorrência, desempenhou um importante papel para a excelência do Programa de Pós-Graduação em Enfermagem da Universidade Federal de Santa Catarina como pesquisadora, fundadora de um dos primeiros grupos de pesquisa no Brasil, e sua contribuição exemplar na criação do Método de Pesquisa Convergente-assistencial. Este método de pesquisa tem contribuído, no país, para o fortalecimento da implementação dos resultados de pesquisa à prática assistencial.

DESCRITORES: Biografia. História da enfermagem. Educação. Pesquisa. Enfermagem. Modelos de enfermagem.

\section{MERCEDES TRENTINI: HER PROFESSIONAL JOURNEY AND INNOVATIVE CONTRIBUTION TO NURSING RESEARCH}

\begin{abstract}
Objective: to historicize the professional journey of Mercedes Trentini and her contribution to Brazilian nursing according to her biography. Method: a qualitative study with a socio-historical approach, whose data were collected through the Oral Biographical History and Documentary Research method.

Results: four categories were established from the analysis of the data: 1) Her insertion in the nursing world and in the Undergraduate Course; 2) Her journey in the Post-Graduate Nursing course; 3) The creation of the Research Center for Nursing and Health Care for People with Chronic Diseases; And 4) The paths taken to create the Convergent-Care Research.

Conclusion: Professor Mercedes Trentini characterized herself as an original, innovative person, committed to the nursing profession and, as a result, played an important role contributing to the excellence of the Nursing Graduate Program of the Universidade Federal de Santa Catarina as researcher and founder of one of the first research groups in Brazil, and her exemplary contribution to the creation of the Convergent-Care Research Method. In Brazil, this research method has contributed to the strengthening of the implementation of the research results to care practice.
\end{abstract}

DESCRIPTORS: Biography. History of nursing. Education. Search. Nursing. Nursing models. 


\title{
MERCEDES TRENTINI: LA TRAJETORÍA PROFESIONAL Y SU CONTRIBUCIÓN EN LA INNOVACIÓN DE LA INVESTIGACIÓN EN LA ENFERMERÍA
}

\begin{abstract}
RESUMEN
Objetivo: historizar la trayectoria profesional de Mercedes Trentini y su contribución a la enfermería brasileña, a partir de su biografía. Método: estudio cualitativo de abordaje socio-histórico, cuyos datos fueron recolectados a través del método de la Historia Oral Biográfica y de la Investigación Documental.

Resultados: a partir del análisis de los datos se establecieron cuatro categorías: 1) la inserción en el mundo de la enfermería y en el Curso de Graduación; 2) La trayectoria en el Postgrado en Enfermería; 3) La creación del Núcleo de Investigación en Enfermería y Salud en el cuidado de las personas con enfermedades crónicas; Y 4) los caminos trillados para la creación de la Investigación Convergente-asistencial.

Conclusión: la Profesora Mercedes Trentini se caracterizó como una persona original, innovadora, comprometida con la profesión de enfermería, y, en consecuencia, desempeñó un importante papel para la excelencia del Programa de Post-Graduación en Enfermería de la Universidad Federal de Santa Catarina como Investigadora, fundadora de uno de los primeros grupos de investigación en Brasil, y su contribución ejemplar en la creación del Método de Investigación Convergente-asistencial. Este método de investigación ha contribuido, en el país, al fortalecimiento de la implementación de los resultados de investigación a la práctica asistencial.

DESCRIPTORES: Biografía. Historia de la enfermería. Educación. Búsqueda. Enfermería. Modelos de enfermería.
\end{abstract}

\section{INTRODUÇÃO}

Em 18 de dezembro de 1960, através da Lei n. 3.849, de 18/12/1960, sancionada pelo presidente da República Juscelino Kubitschek de Oliveira, foi criada a Universidade Federal de Santa Catarina (UFSC), reunindo as Faculdades de Direito, Medicina, Farmácia, Odontologia, Filosofia, Ciências Econômicas, Serviço Social e Escola de Engenharia, que já existiam como cursos independentes na cidade de Florianópolis-SC. ${ }^{1}$ Com isso, iniciaram-se os movimentos para a criação de novos cursos.

A intenção de ser criado um Curso de Graduação em Enfermagem partiu da Diretoria da Associação Brasileira de Enfermagem de Santa Catarina, que em 1966, enviou à Reitoria da UFSC, um memorial contendo as razões e justificativas para a implantação do referido Curso. O mesmo foi criado somente em 24 de janeiro de 1969, através da Resolução n. 02/69/ UFSC, tendo sido o primeiro Curso de Enfermagem em Santa Catarina, e era coordenado inicialmente pela Professora Eloita Neves Arruda que, posteriormente, juntamente com as professoras contratadas, foram expandindo as atividades administrativas e científicas do Departamento de Enfermagem. ${ }^{2-3}$

Em 1974, as professoras do Departamento de Enfermagem, percebendo as necessidades de aprimorar ainda mais seu corpo docente, frente às necessidades do país, estabeleceram um contato com a Pró-Reitoria de Ensino e Pesquisa, para discutir o assunto e, consequentemente, o Pró-Reitor designou então uma comissão* para elaborar um projeto de Curso de Especialização em Enfermagem. Essa comissão, após considerar todas as informações obtidas, sugeriu a criação de um Curso de Pós-Graduação em nível de mestrado. ${ }^{4-5}$

O Departamento de Enfermagem acatou a ideia, estimulado pela Reitoria, através da Portaria n. 28, de 27/01/76, do Reitor Roberto Mündell de Lacerda. O Curso de Mestrado em "Saúde do Adulto" teve início em março de 1976, com dez alunos. A coordenação temporária do Curso ficou sob a responsabilidade da professora Ingrid Elsen, que já havia participado do planejamento e organização do mesmo. Administrativamente, o Curso foi instalado junto ao Departamento de Enfermagem, tendo sido destacada uma secretaria da Pró-Reitoria de Planejamento para auxiliar o referido Curso. ${ }^{4-6}$

A Pós-Graduação atendia a política brasileira de desenvolvimento de incentivo à capacitação docente, com a criação de Cursos de Pós-Graduação lato e stricto sensu em todo o Brasil. Na enfermagem, esta teve início em 1972, na Escola de Enfermagem Anna Nery, da Universidade Federal do Rio de Janeiro, quando a mesma iniciou o Mestrado em Enfermagem Fundamental. ${ }^{4}$

Segundo o último relatório da Coordenação de Aperfeiçoamento de Pessoal de Nível Superior (Capes) de 2013, hoje, no Brasil, existem 96 Programas de Pós-Graduação stricto sensu em Enfermagem, sendo 49 Cursos de Mestrado Acadêmico, 34 Cursos de Doutorado e 19 na modalidade Mestrado Profissional. ${ }^{7}$

Em 1992, foi criado o Curso de Doutorado em Enfermagem na UFSC, e a primeira turma iniciou em março de 1993. Este Programa capacita enfermeiros e enfermeiras, bem como profissionais da área da

Comissão designada pela Portaria n. 231/74, do Pró-Reitor de Ensino e Pesquisa, Professor Samuel Fonseca: as Professoras do Departamento de Enfermagem Eloita Pereira Neves, Ingrid Elsen, Nelcy Terezinha Coutinho Mendes e Rosita Saupe. 
saúde, em nível avançado, para a produção de conhecimentos em saúde e para assumir papel de liderança no campo educacional, assistencial e político da área. ${ }^{3}$

Nesse contexto, a professora Dra. Mercedes Trentini destaca-se como uma das personagens marcantes do Programa de Pós-Graduação em Enfermagem (PEN/UFSC), tendo papel fundamental em decorrência de sua formação, sua produção científica e principalmente por ter introduzido no Programa de Pós-Graduação, conhecimentos originais e inéditos. Sua linha de investigação sempre esteve relacionada às doenças crônicas, sendo criadora do Núcleo de Pesquisa em Enfermagem e Saúde no Cuidado a Pessoas com Doenças Crônicas (NUCRON) em 1986 e, posteriormente, foi uma das precursoras da Pesquisa Convergente assistencial, junto à Dra. Lygia Paim.

Considerando a importante participação para o desenvolvimento da enfermagem catarinense e brasileira é que decidimos realizar este estudo biográfico, apresentando a trajetória histórica e científica da professora Dra. Mercedes Trentini.

As biografias ou trajetórias de vida das enfermeiras têm sido utilizadas amplamente na enfermagem com o intuito de ressaltar o desenvolvimento de uma área profissional específica, orientar a criação de escolas de enfermagem e associações profissionais, desenvolver teorias aplicadas a enfermagem e investigar os avanços sociais e políticos da profissão. ${ }^{8}$

O Laboratório de Estudos de História do Conhecimento da Enfermagem e Saúde (GEHCES), vinculado ao PEN/UFSC desde sua criação, em 1995, vem realizando a historiografia da enfermagem catarinense e brasileira. Ao longo dos anos, tem contribuído na produção de conhecimentos acerca da história das instituições, da identidade profissional na enfermagem, do cuidado à saúde, em especial vinculado às doenças crônico-degenerativas, e também vem realizando estudos biográficos de importantes líderes que se destacaram na enfermagem catarinense e brasileira. . $^{2,-10}$

Este estudo tem como objetivo historicizar a contribuição da Professora Mercedes Trentini para a enfermagem brasileira, a partir de sua biografia.

\section{MÉTODO}

Trata-se de uma pesquisa qualitativa biográfica de abordagem sócio-histórica, cujos dados foram obtidos a partir de uma entrevista realizada com a própria professora Dra. Mercedes Trentini. Utilizou-se o Método de História Oral Biográfico e consultas realizadas a outras fontes documentais como: artigos científicos, currículo lattes da personagem biografada e capítulos de livros relacionados à temática. A entrevista foi realizada em novembro de 2011 em sua residência, na cidade de Florianópolis, com duração aproximada de duas horas. A entrevistada foi orientada quanto à pesquisa, sobre o direito de participar ou não, do Termo de Consentimento Livre e Esclarecido (TCLE) e da Carta de Cessão. Após a transcrição da entrevista, foi realizada validação da mesma pela biografada, a qual autorizou a sua utilização, após alguns ajustes de informações.

Os dados foram analisados através do Método de Análise de Conteúdo, ${ }^{11}$ sendo estabelecidas as seguintes categorias: A inserção no mundo da Enfermagem e no Curso de Graduação; A trajetória na Pós-Graduação em Enfermagem; A criação do Núcleo de Pesquisa em Enfermagem e Saúde no Cuidado a Pessoas com Doenças Crônicas; e Os caminhos trilhados para a criação da Pesquisa Convergente-assistencial. Esta pesquisa foi norteada pelos princípios éticos da Resolução 466/12 do Conselho Nacional de Saúde, e aprovada pelo Comitê de Ética em Pesquisa da UFSC, com o Parecer n. 374/ 008.

\section{RESULTADOS}

\section{A inserção no mundo da enfermagem e no Curso de Graduação}

Mercedes Trentini (Figura 1), filha de Francisco Trentini e Elzira Trentini, nasceu em 14 de maio de 1931, na cidade de Rio dos Cedros, Santa Catarina. Viveu até os dez anos de idade em sua cidade natal com seus pais e dez irmãos. Era a filha caçula num universo constituído por cinco homens e cinco mulheres.

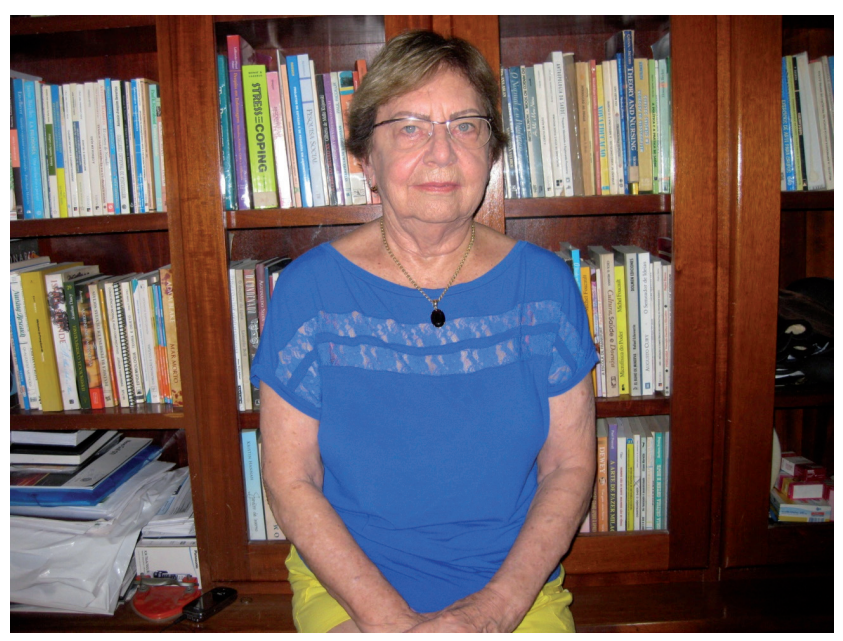

Figura 1 - Professora Dra. Mercedes Trentini Florianópolis-SC, 2016 
Ainda na adolescência, na década de 1940, iniciou seu período de postulado no Colégio das Irmãs da Divina Providência, e continuou sua formação religiosa nessa congregação, tornando-se noviça. Chegou até mesmo a fazer os votos para sua posterior consagração religiosa. As ordens religiosas como a Congregação da Divina Providência começaram a se preocupar com a situação dos hospitais a partir da década de 1950.

Na época, não havia enfermeiras diplomadas. Mercedes, que possuía experiência, passou então a atuar no Colégio Coração de Jesus e, posteriormente, no Imperial Hospital de Caridade (IHC), ambos localizados, na cidade de Florianópolis. Relata que algumas irmãs buscavam a formação profissional no Curso de Enfermagem e, em seguida, essas mesmas irmãs orientavam as outras quanto à realização dos cuidados aos doentes. Nesse cenário, destaca Irmã Tonsila como uma amiga muito especial que trabalhava na instituição.

Ao longo do tempo, Mercedes percebeu que seria imprescindível fundamentar e aperfeiçoar sua prática assistencial com respaldo no conhecimento teórico-científico da profissão. No intuito de prestar seus serviços em Joinville-SC, enviou uma solicitação ao Prefeito da cidade e, em seguida, foi contratada para trabalhar no Hospital Municipal São José de Joinville, na Unidade do Centro Cirúrgico. O desejo em tornar-se uma enfermeira diplomada fez com que, em 1970, a prefeitura da cidade de Joinville lhe contemplasse com uma bolsa de estudos para que tivesse a possibilidade de ingressar em um Curso Superior de Enfermagem no Rio de Janeiro-RJ. Em 1971, após reflexão sobre sua vida religiosa, e em acordo com a Irmã Superiora da Congregação, desligou-se da Congregação. A maior motivação de Mercedes para cursar enfermagem emergiu da prática adquirida nos vários anos de trabalho em instituições hospitalares no Estado de Santa Catarina. A formação acadêmica ocorreu na Escola de Enfermagem Alfredo Pinto, que integra a Universidade Federal do Estado do Rio de Janeiro (UNIRIO). Neste período, residiu em um pensionato que ficava sob os cuidados de duas irmãs idosas. Este, embora tivesse uma localização que facilitava o acesso à Escola de Enfermagem, além de ser de baixo custo com a moradia, possuía uma infraestrutura um tanto precária para a acomodação das aproximadamente 60 moças que residiam no local.

A sua turma do Curso de Graduação era composta por 60 alunos, entre homens e mulheres, e caracterizava-se por ser uma turma rebelde, pois ao longo dos anos de formação, constantemente teciam críticas construtivas, no intuito de contribuir de algum modo para transformar a realidade acadêmica da época. Esse período foi marcante em sua vida, pois fez amizades valiosas, destacando os colegas Raimunda e Antônio, com os quais se reunia para estudar nos finais de semana.

O Curso, em período integral, constava de disciplinas teóricas e aulas práticas. Mesmo com uma boa relação entre discentes e docentes, Mercedes sempre se considerou uma pessoa muito crítica e, no que se refere à sua formação, realmente acreditava que o ensino universitário tinha muito o que melhorar, pois percebia muitas fragilidades na formação didático-pedagógica dos docentes do Curso. Apesar disso, algumas docentes se destacavam, como uma das professoras da área maternoinfantil, que era muito respeitada pela comunidade médica, devido aos cuidados efetivos prestados aos doentes.

Durante o período de formação acadêmica, Mercedes não participou de movimentos acadêmicos ou grêmios estudantis, pois era o período da ditadura militar, momento histórico marcado pela repressão da liberdade de expressão, especialmente na comunidade acadêmica das instituições de ensino superior. Durante o período de formação acadêmica, dedicou-se somente aos estudos, pois além de ter ingressado no Curso de período integral, deveria ter boas notas para permanecer com o subsídio da bolsa de estudos.

Após a conclusão da Graduação em Enfermagem, em 1973, retornou para Joinville, onde necessariamente deveria permanecer por no mínimo dois anos, devido ao financiamento de seus estudos pela prefeitura da cidade. Reiniciou suas atividades como supervisora do Serviço de Enfermagem do Hospital Municipal São José. Nesta época, já havia uma enfermeira na instituição, que foi deslocada para a função de Coordenadora do Curso de Auxiliar em Enfermagem, que estava sendo estruturado no hospital. O corpo docente do Curso era constituído, por outras duas enfermeiras, dentre estas, a enfermeira Cleusa Rios Martins, que, no ano de 1986, passou a integrar o Departamento de Enfermagem da UFSC, aposentando-se nesta instituição.

Após dois anos de atuação no Hospital Municipal de São José, os recursos humanos da instituição permaneciam muito frágeis, tanto na assistência médica quanto nos cuidados de enfermagem. A assistência de enfermagem, em sua maioria, ainda era executada por leigos ou por auxiliares de enfermagem formados dentro do próprio hospital. Essa situação fez com que Mercedes deixasse a cidade de Joinville-SC em busca de novos desafios 
profissionais, como expressa em uma de suas falas: eu sempre queria mais, sempre fui uma pessoa que vivia o futuro, nunca me contentei com pouco.

Assim, em 1975, vislumbrou a capital catarinense, Florianópolis, como uma oportunidade para desenvolver seu potencial como enfermeira assistencial. Passou a atuar no Hospital Governador Celso Ramos (HGCR), em Florianópolis, onde permaneceu por aproximadamente um ano. No ano seguinte, em 1976, prestou concurso público e foi aprovada para atuar como docente no Curso de Graduação em Enfermagem da UFSC. Na época, a professora Rosita Saupe era chefe do Departamento de Enfermagem. Dentre as professoras que ingressaram nesse período, recorda de algumas colegas como Alacoque Lorenzini Erdmann, da área de Administração, e Edilza Maria Ribeiro, da área de pediatria.

Os laços com o HGCR continuaram por meio de sua atuação como docente do estágio supervisionado de enfermagem na Unidade de Terapia Intensiva (UTI). Além desta disciplina, também ministrava algumas disciplinas teóricas. Entretanto, foi na supervisão de estágio na UTI do HGCR que desenvolveu um modelo de assistência de enfermagem muito consistente junto aos seus alunos, passando a ser reconhecida, inclusive, pelo corpo médico da Unidade, que solicitava constantemente seus cuidados e orientações. A Professora Mercedes destaca que a postura profissional adotada foi fundamental para o reconhecimento da qualidade assistencial dos graduandos da UFSC, relatando: [...] eu sempre tive bom relacionamento com os médicos, eu respeitava, mas eles também me respeitavam [...] e eu acredito também que a postura que a gente se coloca faz com que a gente seja respeitada.

\section{A trajetória na Pós-Graduação em Enfermagem}

A Professora Mercedes relata que o PEN/ UFSC iniciou com o Curso de Mestrado em 1976, sob a coordenação da Professora Ingrid Elsen. Outras professoras do curso de enfermagem também integravam a pós-graduação stricto sensu, como Eloíta Pereira Neves e Maria Albertina Bráglia Pacheco, que estudaram na Escola de Enfermagem Anna Nery, da Universidade Federal do Rio de Janeiro (UFRJ). Importante ressaltar que quando retornou para Florianópolis, Maria Albertina assumiu a coordenação do PEN/UFSC em 1977.

Neste mesmo ano, Mercedes ingressou no Mestrado como aluna regular da segunda turma do Programa. Durante esse período, teve aulas com uma das personalidades mais marcantes da enfer- magem nacional: a Professora Wanda de Aguiar Horta. A Professora Mercedes comenta em uma de suas falas sobre a importância da vinda desta Professora: não tínhamos grandes professores, mesmo da enfermagem. A que vinha, que era uma boa professora, era a Wanda de Aguiar Horta. Ela vinha de São Paulo com uma mala cheia de bibliografias, porque aqui não tinha e não tinha internet na época. Praticamente no mesmo período, a Professora Lúcia Hisako Takase Gonçalves veio da cidade de São Paulo para reforçar a equipe de professores do PEN/UFSC.

A Professora Mercedes relata que, na sua dissertação de Mestrado, realizou estudo com pacientes portadores de insuficiência renal, dependentes de hemodiálise. Sua orientadora foi a Professora Lúcia Hisako Takase Gonçalves, e contou com o precioso apoio da Professora Maria de Lourdes de Souza, que estava, nessa época, realizando seu Doutorado na Universidade de São Paulo (USP). A Professora Mercedes concluiu o Mestrado no primeiro semestre do ano de 1980.

Neste mesmo período havia uma intensa mobilização junto à Capes para que os professores do PEN/UFSC cursassem o Doutorado no exterior. Uma das incentivadoras para que fizesse a seleção para o Doutorado no exterior foi a Professora Alacoque Lorenzini. A seleção exigia o domínio da língua inglesa e entrevista com os conselheiros da Capes.

A Professora Mercedes não tinha certeza se seria aprovada no processo seletivo para o Doutorado, pois relata ter dito na entrevista com os conselheiros da Capes que não possuía fluência na língua inglesa e não tinha certeza se queria sair do país para estudar. Entretanto, 15 dias após sua entrevista, recebeu um telefonema de Brasília, comunicando sua aprovação para realização de um Curso de Especialização nos EUA, com financiamento da Capes, com uma bolsa de estudos durante um período de 12 meses. Mercedes ficou surpresa e feliz com a notícia. Questionou então os motivos de sua aprovação junto aos responsáveis da Capes e lhe foi dito que haviam recebido a informação de que a Professora Mercedes Trentini era uma pessoa com grande potencial, e tinham certeza de que poderiam investir na sua formação.

No período em que iniciou uma nova etapa em sua carreira profissional, relata: eu, como sempre, fui muito corajosa. Como a Ingrid já estava fazendo doutorado lá, na época, então escrevi uma carta para ela e fui, na cara e na coragem, sem falar inglês. Primeiro eu entrei em uma escola de inglês, depois eu assisti às aulas na universidade. Em 1981, instalou-se na cidade de São Francisco, no Estado da California, onde permane- 
ceu por um ano e seis meses cursando especialização na University of California desenvolvendo o estudo Nursing care of chronic patients, e orientada pela Dra. Elizabeth C. Carroll.

Assim que retornou ao Brasil, em 1982, fez contato telefônico com os responsáveis da Capes, para assegurar sua permanência no exterior com o recebimento de uma nova bolsa de estudos, a fim de cursar o doutorado. A Professora Mercedes retornou no mesmo ano para os EUA, agora na University of Alabama, situada na cidade de Birmingham, ingressando no Curso de Doutorado, e destacando-se como a única estrangeira de sua turma.

No período em que cursou o Doutorado, além de aprofundar seus estudos nas teorias e ciências peculiares à área da enfermagem, aprendeu intensivamente os aspectos relacionados à pesquisa científica quantitativa, com a utilização de estatística avançada. A Professora Mercedes comenta que, na época, não havia acesso à internet, contudo, havia bibliotecas com ótima infraestrutura, que contemplava vasta literatura científica: as universidades de lá têm um suporte estudantil que vocêé obrigado a estudar. É uma coisa fantástica aquilo. Imagina agora! Isso há quantos anos? Mais de trinta anos.

Ainda no período em que cursou o doutorado nos EUA, a entrevistada refere que aprendeu a realizar pesquisas usando o método qualitativo e quantitativo, e discorre sobre a rica experiência que teve com os avanços tecnológicos que permitiram o aperfeiçoamento das técnicas de coleta e interpretação dos dados pesquisados: ali começamos também a lidar com o computador. Naquela época se começou a lidar com os microcomputadores. Nós fazíamos as análises estatísticas tudo no computador. Era um centro de computação. Batíamos cartão para obter todos os dados, $e$ aí nós aprendemos a interpretar a análise do computador. A gente aprendeu a interpretar. Aprofundou seus estudos em estatística avançada, chegando a participar de aproximadamente seis cursos nessa área, o que contribuiu de modo significativo para o desenvolvimento de ainda mais estudos qualitativos e quantitativos na área da enfermagem. Em 1985, sob a orientação da Dra. Suzana Gennaro, defendeu a tese de Doutorado intitulada Nurse's decisions in dialysis patients care.

Após a conclusão do Doutorado e com vasta experiência em pesquisas qualitativas e quantitativas, a Dra. Mercedes retorna definitivamente para o Brasil em 1986, para continuar a atuar no Departamento de Enfermagem e no PEN/UFSC. Houve algumas dificuldades para readaptar-se ao cenário cultural e socioeconômico da época, mas, gradativa- mente, conseguiu passar por essa fase de transição em sua vida, voltando a integrar-se novamente ao cotidiano universitário.

Durante a década de 1980, a pesquisa quantitativa já estava muito difundida na enfermagem. Contudo, os avanços na interpretação das análises quantitativas, como os dados estatísticos complexos, eram praticamente inexistentes. Já a pesquisa qualitativa iniciou de modo tênue, mas alcançou um patamar de reconhecimento científico significativo na enfermagem, que permanece nos dias atuais. Entretanto, a Dra. Mercedes demonstra sua preocupação quando faz reflexões sobre as fragilidades do rigor científico existentes atualmente nessa modalidade de pesquisa: [...] aqui no Brasil também a pesquisa qualitativa está ficando meio superficial, podemos dizer assim, não todas, porque temos pesquisadores bons. 'Pesquisa qualitativa é só colocar umas frases que as pessoas falam.' Mas pesquisa não é isso, pesquisa é uma coisa séria. Então, a minha maior decepção e descontentamento com a pesquisa é isso aí.

\section{A criação do Núcleo de Pesquisa em Enfermagem e Saúde no Cuidado a Pessoas com Doenças Crônicas}

O interesse da Dra. Mercedes pelo estudo das doenças crônicas surgiu quando ainda trabalhava no Hospital Governador Celso Ramos, devido ao número expressivo de pacientes com insuficiência renal crônica. Essa temática permeou toda sua trajetória acadêmica, desde a realização de sua dissertação de Mestrado no PEN/UFSC, até sua tese de Doutorado elaborada nos EUA. Quando regressou ao Brasil para atuar na docência, permaneceu trabalhando com doenças crônicas nas disciplinas que ministrava no PEN/UFSC.

Pode-se considerar que, em Santa Catarina, a Dra. Mercedes Trentini foi uma das pioneiras nos estudos relacionados às doenças crônicas. Assim que retornou ao país, em 1986, idealizou um projeto em parceria com as Professoras Denise Guerreiro Vieira da Silva e Marta Verdi, que tinha por objetivo traçar o perfil das doenças crônicas nos hospitais de Florianópolis. Por meio desses estudos, foi possível identificar a proporção de pessoas com doenças crônicas, bem como conhecer quais eram as doenças crônicas mais frequentes nos pacientes hospitalizados, e ainda, como conviviam com essa situação em seu cotidiano.

A partir da evidência dos dados tão expressivos e alarmantes sobre as doenças crônicas, as professoras perceberam a necessidade da construção 
de um grupo de pesquisa para desenvolver estudos na área. Assim, em 1987, é criado o NUCRON, pelas professoras Mercedes Trentini e Denise Guerreiro Vieira da Silva. As duas professoras passaram então a orientar diversos trabalhos científicos com aderência aos temas de interesse do grupo. A princípio, os trabalhos foram voltados, em grande parte, à pesquisa quantitativa, e com a gradativa ascensão da pesquisa qualitativa na área de enfermagem, os trabalhos passaram a ser orientados pela nova abordagem metodológica. Dentre os trabalhos desenvolvidos no NUCRON, a Dra. Mercedes considera que todos têm igual importância, no entanto, ressalta a relevância dos estudos com pessoas ostomizadas, os quais deram origem ao Grupo de Apoio ao Ostomizado (GAO). Em decorrência da criação desse grupo, surgiu uma parceria efetiva com o NUCRON, e foram realizadas inúmeras pesquisas nessa temática, com destaque para a participação ativa da Professora Mercedes.

A Dra. Mercedes aposentou-se no ano de 1991 e, em seguida, recebeu diversos convites para trabalhar em universidades de todo o país. Em 1992, passou a atuar como docente da UNIRIO, na cidade do Rio de Janeiro, como professora visitante. Logo após, foi contratada pela Rede de Pós-Graduação em Enfermagem da Região Sul (REPENSUL) para lecionar em Curitiba, na Universidade Federal do Paraná (UFPR), na qual permaneceu por quatro anos. Ainda trabalhou nas Universidades do Contestado (UnC), Campus de Concórdia-SC, de 1998 a 2000, e na Pontifícia Universidade Católica do Estado do Paraná (PUC-PR), na cidade de Curitiba, de 2001 a 2005. Em seguida, voltou para Concórdia, com o intuito de lecionar novamente na UnC, na qual atuou como docente em 2008.

A Dra. Mercedes também atuou em Porto Alegre, na PUC do Rio Grande do Sul. Sua vasta experiência em realizar estudos com pesquisadores com formações distintas fez com que Mercedes se comprometesse com a práxis da interdisciplinaridade no meio científico: tem que interagir sim, para o bem da ciência, para o bem da saúde. Relata inclusive que a maioria de seus orientandos não era enfermeiro, comentando que havia profissionais dos Cursos de Letras, Educação Física, Fisioterapia, Biologia e Psicologia.

\section{Os caminhos trilhados para a criação da Pesquisa Convergente-assistencial}

No campo da pesquisa científica, a Dra. Mercedes considera que uma de suas maiores contri- buições, em parceria com a Professora Dra. Lygia Paim, sua amiga e parceira, foi a criação de uma metodologia de pesquisa inovadora, cujo objetivo é aliar a pesquisa com a prática assistencial, denominada Pesquisa Convergente-assistencial (PCA). Esta parceria iniciou na década de 1990, na época em que a professora Dra. Lygia Paim finalizou suas atividades de professora visitante na UFSC e recebeu um convite da Professora Dra. Mercedes Trentini para participar das atividades do NUCRON, como pesquisadora. A partir deste momento, as professoras iniciaram suas pesquisas voltadas para a prática assistencial.

Durante o desenvolvimento da disciplina de "Prática Assistencial" realizada no Curso de Mestrado, as alunas elencavam um referencial teórico-filosófico de sua preferência e, em seguida, praticavam esses pressupostos em suas atividades assistenciais. Desse modo, as enfermeiras aprendiam a unir a teoria com a prática. Segundo a Dra. Mercedes, a disciplina contribuía para que as alunas compreendessem que, em determinadas situações, a teoria aplicada na prática necessitava de reformulações para adequar-se realmente à prática assistencial. A conclusão da disciplina exigia a elaboração de um relatório sobre a atividade desenvolvida.

Diante de expressivos resultados obtidos com as práticas na disciplina, ela sugeriu à Dra. Ingrid Elsen, que também atuava na mesma, que o relatório final desta disciplina pudesse ser considerado o princípio da própria dissertação de Mestrado. Assim, essa proposta foi levada a um grupo de alunas do curso de Mestrado. Inicialmente, as discentes estranharam a sugestão, questionando inclusive a cientificidade da proposta metodológica. Contudo, após terem a compreensão da magnitude do trabalho a ser realizado, dentre as 21 alunas do curso, apenas uma delas não aceitou a sugestão.

Mercedes expõe que, no decorrer dos anos, a frequência com que as turmas de Mestrado utilizavam essa disciplina como alicerce para suas dissertações era ascendente: [...] e aquilo ficou tão bom, o trabalho ficou tão consistente, que estava parecendo mesmo uma pesquisa. Havia alunas que elaboravam suas próprias teorias. Aí veio a ideia: isso pode ser uma pesquisa! Foi aí que começamos. Foram dez anos de experiência com esses alunos, e foi aumentando até que, em 1999, decidimos escrever um livro divulgando o método. Este foi intitulado Pesquisa Convergente-assistencial. Segundo a entrevistada: eu acho que ela, a PCA, tem futuro, porque a nossa intenção foi fazer com que as enfermeiras da prática pudessem estudar a sua própria prática dentro do ambiente de trabalho. 
Quando reflete sobre os momentos mais marcantes de sua vida, a Dra. Mercedes destaca: $o$ que mais marcou a minha vida foi o curso de doutorado, porque foi um salto de qualidade que eu tive, e graças a Deus que eu fui para os Estados Unidos. Também eu vou dizer que não foi sem sofrimento, foi com muito sofrimento, muita luta. E o segundo, eu acho que foi a PCA, Pesquisa Convergente-assistencial, porque é um desafio é muita coragem...

\section{DISCUSSÃO}

Pensar e escrever a história do presente permite compreender o contexto histórico de desenvolvimento da enfermagem enquanto profissão, especialmente do ponto de vista que nos interessa, que é refletir sobre os modos como a identidade profissional é tratada pelos diversos autores ou enfatizar a importância da história da enfermagem para compreensão da área e da construção identitária individual e coletiva. ${ }^{12}$ Neste sentido, temos as biografias que revelam a história de pessoas e do papel essencial que estas tiveram no desenvolvimento profissional da enfermagem. ${ }^{8}$

A biografia tem sido utilizada pelos historiadores da história oral a fim de resgatar a memória de pessoas importantes para a história. É entendida pelos historiadores como o "mergulho na alma", a escrita de si, revelando a intimidade do entrevistado, assumindo dimensões como a memória ou tradição oral familiar, as memórias. ${ }^{13}$

A trajetória profissional de Mercedes Trentini se assemelha, em seu início, à carreira de muitas outras enfermeiras que, a partir de sua atuação como religiosas em hospitais ou escolas, decidiam por uma carreira profissional. A enfermeiras religiosas que atuavam nos hospitais, dividiam o seu trabalho, na maioria das vezes, atuando nos serviços gerais, nas atividades administrativas e também dirigindo o trabalho de enfermagem. ${ }^{10}$ Também no Imperial Hospital de Caridade (IHC), como era chamado na época, a equipe de enfermagem era composta pelas Irmãs da Divina Providência, auxiliada por atendentes subalternos e por alguns ex-doentes que não tinham para onde ir, pois não contavam com o apoio da família ou comunidade. ${ }^{14}$ Vale ressaltar que a atuação de Mercedes Trentini como religiosa se prolongou por aproximadamente três décadas, em vários hospitais do Estado de Santa Catarina, em cidades como Blumenau, Rodeio e Joinville exercendo seu trabalho especialmente em Centro Cirúrgico e, posteriormente, nas Unidades de Terapia Intensiva, continuando a fazê-lo após o encerramento de sua vida religiosa.
A busca por novos caminhos e possibilidades de se desenvolver teórica e cientificamente foi o que impulsionou Mercedes Trentini a investir profissionalmente na carreira acadêmica. Este desenvolvimento articulava-se à busca do aperfeiçoamento oferecido pelos Programas de Pós-graduação existentes no país ou em outros países. Tanto a criação da Capes, como do CNPq, o incentivo à pesquisa e a criação dos Cursos de Pós-graduação, possibilitaram a oportunidade não apenas de bolsas de estudos para o Mestrado e Doutorado no Brasil, como também em outros países e, mais especialmente, nos Estados Unidos.

A política de distribuição de bolsas da Capes no exterior permitiu que os intercâmbios acadêmicos internacionais brasileiros não ficassem restritos à circulação de elites: eles se inseriram no campo das políticas públicas de educação e na formação de quadros para a ciência e a tecnologia. ${ }^{15}$ Sem dúvida alguma, como previram os membros/conselheiros/ consultores da Capes, ao selecionarem a professora Mercedes para receber bolsa para realizar o doutorado no exterior, ela realmente tinha um grande potencial, tornando-se uma das enfermeiras docentes mais consagradas do país.

$\mathrm{Na}$ área de enfermagem, inúmeros enfoques teórico-metodológicos têm sido utilizados, contribuindo para o enriquecimento do corpo de conhecimento das pesquisas realizadas. Com o seu desenvolvimento, foram surgindo opções metodológicas capazes de abrir caminhos que possibilitassem uma maior clareza dos fenômenos estudados e, com isso, a aproximação com os métodos qualitativos e quantitativos. ${ }^{16}$

Ao retornar do doutorado, a Professora Dra. Mercedes Trentini focou a sua investigação na linha de pesquisa relativa aos clientes em situação crônica de saúde, o que coadunava com a evidência dos dados alarmantes sobre as doenças crônicas no país. Esta, junto à Professora Dra. Denise Guerreiro, percebeu a necessidade da construção de um grupo de pesquisa para desenvolver estudos na área. Essa situação foi um incentivo para que, em 1987, fosse criado o NUCRON.

O NUCRON é um grupo que busca desenvolver conhecimento teórico-prático relacionado à saúde de pessoas que vivem com uma condição crônica de saúde, por meio da pesquisa, do ensino e da assistência. As áreas de interesse do grupo envolvem os temas relacionados à antropologia da saúde, qualidade de vida de pessoas com problemas respiratórios crônicos, ostomias, diabetes, problemas renais crônicos e problemas cardiovasculares. 
Também pesquisa sobre educação em saúde, com foco na abordagem construtivista, desenvolvendo a educação em grupos, especialmente os grupos de convivência. ${ }^{17} \mathrm{O}$ NUCRON vem trabalhando ativamente em estudos nesta área, tendo publicado, em 2014, o livro intitulado "Condições crônicas e cuidados inovadores em saúde", também de autoria de Mercedes Trentini, Lygia Paim e Denise Guerreiro, no qual tratam dos estudos realizados pelo grupo nesta área e do uso da PCA nos mesmos. ${ }^{18}$

A idealização do Método de Pesquisa Convergente-assistencial pelas Dras. Mercedes Trentini e Lygia Paim, surgiu na disciplina denominada "Prática Assistencial". Esta tinha por objetivo clarificar a definição do problema de pesquisa e contribuir na busca do método mais adequado para fazer o levantamento dos dados empíricos. ${ }^{19}$

Na abordagem metodológica PCA, as enfermeiras têm a possibilidade de pesquisar sobre a sua prática assistencial no seu próprio ambiente de trabalho. Exige a participação ativa dos sujeitos de pesquisa, objetivando a resolução ou minimização de problemas na prática, ou para a realização de mudanças e/ou introdução de inovações nas práticas de saúde. ${ }^{20-21}$

A PCA atualmente é utilizada em vários Programas de Pós-graduação em todo o Brasil, não apenas em cursos acadêmicos, como também nos mestrados profissionais e, por ser uma modalidade de pesquisa que sustenta estreita relação com a situação social e objetiva encontrar soluções para problemas, realizar mudanças e introduzir inovações na esfera social.

Em estudo bibliométrico realizado em 2012 acerca da contribuição da PCA na construção do conhecimento de enfermagem e saúde, produzido em cursos de Mestrado e Doutorado no Brasil, foram detectadas 67 dissertações e seis teses que utilizaram a PCA como modalidade de pesquisa, entre os anos de 2000 e 2008. Nestes estudos foi verificado a busca de respostas aos problemas da prática, contribuindo com novas possibilidades de intervenção nos diversos cenários, não somente da enfermagem, mas de outras profissões da área da saúde. ${ }^{22}$ Corroborando com esta informação, foi realizada uma revisão integrativa acerca do uso da PCA publicada em sete periódicos brasileiros no período de 2005 a 2010. Nestes, foram selecionados 19 artigos que retrataram a crescente utilização dessa metodologia na produção científica da enfermagem brasileira. ${ }^{23}$

A PCA vem sendo discutida amplamente quando se analisa a importância dos modelos de cuidado de enfermagem para a consolidação dessa disciplina. ${ }^{24}$ Esta fornece a convergência entre a academia e a prática de saúde e enfermagem, auxiliando em uma prática segura, sistematizando o cuidado de enfermagem, levando os enfermeiros a adotarem posturas de construção de conhecimento mais sólidas.

Estes estudos relatados mostram que Mercedes Trentini, ao longo de sua trajetória profissional, acadêmica e científica, nos deixa um legado essencial e importante que ultrapassa as barreiras das salas de aula para se constituir em um modelo de ensinar e pesquisar. Ela continua atuando ativamente como pesquisadora e produtora de novos conhecimentos, aprofundando cada vez mais seus estudos relativos a PCA, visando aprimorá-la, e ampliando cada vez mais a sua utilização no Brasil e América Latina.

Como limitações do presente estudo, pode-se citar a escassez de artigos que descrevam e discutam a importância da Professora Mercedes Trentini, tanto no que se refere a pesquisa, quanto no ensino e na pós-graduação no país. Isto, por sua vez, também é uma fortaleza, pois permite apontar a importância desta personalidade no cenário nacional e internacional. Com a implementação da PCA nos Cursos de Mestrado e Doutorado do PEN/UFSC, os estudantes podem aprender esta metodologia e levar para as suas instituições e países de origem.

\section{CONCLUSÃO}

Os resultados demonstram o importante papel que a Professora Dra. Mercedes Trentini desempenhou não somente na pós-graduação em enfermagem da UFSC, mas também em outros cursos de graduação e pós-graduação da Região Sul e Sudeste do país. Estes apontam sua contribuição para a enfermagem brasileira e até mesmo para outras áreas do conhecimento. Sempre se destacou por estar à frente de seu tempo, buscando novos desafios e aprofundando seus conhecimentos na área da pesquisa qualitativa; culminando na estruturação do método de pesquisa com relevante inserção em âmbito nacional, ao qual denominou PCA, e tem sido utilizado amplamente no contexto da pesquisa de enfermagem.

Este estudo biográfico contribui de forma exemplar para a enfermagem catarinense, brasileira, e até mesmo internacional, de uma grande líder. Sua biografia pode ser considerada um modelo para as futuras gerações de enfermeiras. Para a profissão, ela deixa um legado, o conhecimento científico produzido e as possibilidades de modificação na prática assistencial. Quando conseguiu agregar 
teoria e prática e prática e teoria, conseguiu intervir na prática. Para o PEN/UFSC, a Dra. Mercedes Trentini caracterizou-se como uma professora original, inovadora e brilhante. Finalmente, a contribuição do estudo biográfico para a memória da profissão, possibilita um amplo entendimento das nossas origens, dos nossos sucessos e dilemas, e um vislumbrar de novas perspectivas.

\section{REFERÊNCIAS}

1. Rodrigues I. A UFSC na década de 1960: outras histórias. In: Neckel R, Küchler ADC, organizadoras. Universidade Federal de Santa Catarina. UFSC 50 anos: trajetórias e desafios. Florianópolis (SC): Editora da UFSC; 2010.

2. Borenstein MS, Oliveira ME, Santos EKA, Maliska ICA. Eloita Pereira Neves: baluarte da enfermagem da Universidade Federal de Santa Catarina. Texto Contexto Enferm. [Internet]. 2009 Dec [cited 2016 May 26]; 18(4):759-65. Available from: http:/ / dx.doi. org/10.1590/S0104-07072009000400018

3. Universidade Federal de Santa Catarina (BR). Centro de Ciências da Saúde. Programa de Pós-graduação em Enfermagem. História do Programa [Internet]. Florianópolis (SC): 2016 [cited 2016 May 25]. Available from: http://www.pen.ufsc.br

4. Padilha MICS, Borenstein MS, Maia AR, Guedes JAD, Lessmann JC, Machado CA. Uma história de sucesso: 30 anos da Pós-graduação em Enfermagem da UFSC. Texto Contexto Enferm [Internet]. 2006 Apr [cited 2016 May 26]; 15(spe):20-30. Available from: http:/ / dx.doi. org/10.1590/S0104-07072006000500002

5. Padilha MI, Sousa CN, Pinheiro JT. As Pós-graduações no Centro de Ciências da Saúde. In: Neckel R, Küchler ADC. Universidade Federal de Santa Catarina. UFSC 50 anos: trajetórias e desafios. Florianópolis (SC): Editora da UFSC; 2010.

6. Borenstein MS, Althoff CR, Souza ML. Enfermagem da UFSC: recortes de caminhos e memórias, 1969-1999. Florianópolis (SC): Insular; 1999.

7. CAPES. Resultados da avaliação trienal 2013 por Programa de Pós-graduação. [Internet]. Brasília (DF): 2016 [cited 2016 Jun 16]. Available from: http:// www.capes.gov.br/36-noticias/6908-capes-divulgaresultado-final-da-avaliacao-trienal-2013-aposanalise-de-recursos

8. Padilha MI, Nelson S, Borenstein MS. As biografias como um dos caminhos na construção da identidade do profissional da enfermagem. Hist Cienc SaudeManguinhos [Internet]. 2011 Dec [cited 2016 May 26]; 18(Suppl 1):241-52. Available from: http://dx.doi. org/10.1590/S0104-59702011000500013

9. Borenstein MS, Althoff CR, Maia ARC, Carvalho JB, Espíndola DS, Padilha MI. Ingrid Elsen: a professional career and her dedication to the study of family care. Texto Contexto Enferm [Internet]. 2014 Mar [cited
2016 May 26]; 23(1):83-91. Available from: http:// dx.doi.org/10.1590/S0104-07072014000100010

10. Borenstein MS, Padilha MI, Maia AR, Costa E, Gregório VRP, Espíndola AMK. Ottillie Hammes: pioneira da enfermagem catarinense. Rev Bras Enferm [Internet]. 2009 Apr [cited 2016 May 26]; 62(2):240-45. Available from: http://dx.doi.org/10.1590/S003471672009000200011

11. Bardin L. Análise de conteúdo. Lisboa (PT): Editora Edições 70; 2011.

12. Padilha MI, Ferreira AC, Maliska ICA, Villarinho MV, Zytkuewisz GV, Sell C. Tendências recentes da produção em história da enfermagem no Brasil. Hist. cienc. saude-Manguinhos [Internet]. 2013 June [cited 2016 May 26]; 20(2):695-707. Available from: http:// dx.doi.org/10.1590/S0104-59702013000200019

13. Grypma S. Critical issues in the use of biographic methods in nursing history. In: Lewenson S, Herrman EK. Capturing nursing history: a guide to historical methods in research. New York (US): Springer Publishing Company; 2008.

14. Imperial Hospital de Caridade. Histórico ano de 1926: as Irmãs da Divina Providência. [Internet]. Florianópolis (SC): 2016 [cited 2016 Jun 12]. Available from: http:/ /198.106.92.3/hospital/1926.html

15. Mazza D. Intercâmbios acadêmicos internacionais: bolsas Capes, CNPq e FAPESP. Cadernos de Pesquisa [Internet]. 2009 Mai [cited 2016 Jun 14];39(137):521-47. Available from: http://publicacoes.fcc.org.br/ojs/ index.php/cp/article/view/235/249

16. Silva LMS, Oliveira RNR, Frota MA, Fialho AVM. Pesquisa internacional em enfermagem: tendências temáticas e metodológicas. Rev Bras Enferm [Internet]. 2008 Set [cited 2016 Jun 18]; 61(5):615-9. Available from: http://www.scielo.br/scielo.php?script=sci_ar ttext\&pid=S0034-71672008000500014

17. Universidade Federal de Santa Catarina. Centro de Ciências da Saúde. Programa de Pós-Graduação em Enfermagem. Nucron [Internet]. Florianópolis (SC): 2016 [cited 2016 May 27]. Available from: http:// ppgenf.posgrad.ufsc.br/grupos-de-pesquisa-2/

18. Trentini M, Paim L, Guerreiro D. Condições crônicas e cuidados inovadores em saúde. São Paulo (SP): Editora Atheneu; 2014.

19. Gelbcke FL, Tavares CMA, Matos E, Fertonani HP, Silvestrim ANS, Shiroma LMB et al. Trabalho, saúde, cidadania e enfermagem: produção do conhecimento do Grupo Práxis. Texto Contexto Enferm [Internet]. 2008 Dec [cited 2016 May 26]; 17(4):727-33. Available from: http://dx.doi.org/10.1590/S010407072008000400014

20. Trentini M, Paim L. Pesquisa convergente-assistencial: um desenho que une o fazer e o pensar na prática assistencial em saúde-enfermagem. $2^{\mathrm{a}}$ ed. Florianópolis (SP): Insular; 2004.

21. Trentini M, Paim L. An innovative approach to promote a healthy lifestyle for persons in chronic 
conditions in Brazil. In: Turley AB, Hofmann GC, organizador. Life style and health research progress. Nova York (US): Nova Publishers; 2008.

22. Reibnitz KS, Prado ML, Lima MM, Kloh D. Pesquisa convergente-assistencial: estudo bibliométrico de dissertações e teses. Texto Contexto Enferm [Internet]. 2012 Sep [cited 2016 May 27]; 21(3):702-7. Available from: http://dx.doi.org/10.1590/S0104-07072012000300027

23. Pivoto FL, Lunardi Filho WD, Santos SSC, Lunardi VL. Convergent-assistential research: an integrative review of scientific nursing production. Texto Contexto Enferm. [Internet]. 2013 Sep [cited 2016 May 27]; 22(3):843-9. Available from: http://dx.doi. org/10.1590/S0104-07072013000300034

24. Rocha PK, Prado ML, Silva DMGV. Pesquisa convergente-assistencial: uso na elaboração de modelos de cuidado de enfermagem. Rev Bras Enferm [Internet]. 2012 Dec [cited 2016 May 27]; 65(6):1019-25. Available from: http://dx.doi.org/10.1590/S003471672012000600019 